\title{
Özellik seçimi ve Derin Öğrenmeye Dayalı Parkinson Hastalığı Tespiti
}

\author{
Mehmet Bilal Er ${ }^{1 *}$ \\ 1* Harran Üniversitesi, Mühendislik Fakültesi, Bilgisayar Mühendisliği Bölümü, Şanlıurfa, Türkiye, (ORCID: 0000-0002-2074-1776), bilal.er@harran.edu.tr
} (İlk Geliş Tarihi 27 Ekim 2020 ve Kabul Tarihi 23 Ocak 2021)

(DOI: 10.31590/ejosat.817151)

ATIF/REFERENCE: Er, M. B. (2021). Özellik seçimi ve Derin Öğrenmeye Dayalı Parkinson Hastalığı Tespiti. Avrupa Bilim ve Teknoloji Dergisi, (21), 428-436.

\begin{abstract}
$\ddot{O} \mathbf{z}$
Parkinson hastalığı, motor sistemini etkileyen uzun süreli ciddi bir nörodejeneratif hastalıktır. Yavaşça ilerler ve zamanla hücrelerinin dejenerasyonuna neden olur. Bu hastalığın teşhisi zordur ve toplumdaki yaygın hastalıklardan biridir. Beyindeki dopamin hücrelerinin yetersizliği nedeniyle, vücutta motor ve motor olmayan (konuşma, koku alma) kusurlara yol açar. Parkinson hastalarının çoğunda ses bozukluğu olduğu bilenmektedir. Parkinson hastalarındaki konuşma sinyalleri, normal insanlara kıyasla büyük farklılıklar göstermektedir. Bu araştırmada, Parkinson hastalığının sınıflandırılması için konuşma sinyallerinin akustik özellikleri kullanılarak derin öğrenmeye dayalı yöntem önerilmektedir. İlk adımda akustik özellikler genetik algoritmadan geçirilerek etkin özellikler seçilmiştir. Ayrıca Genetik algoritmanın performansını kıyaslamak için ReliefF özellik seçin algoritmasında kullanılmıştır. İkinci adımında tasarlanan Evrişimsel Sinir Ağı (ESA) mimarisine bu özellikler girdi olarak verilmiştir. Deneyler literatürde yaygın kullanılan veri seti ile yapılmıştır. Bu veri seti iki sınıftan oluşmaktadır ve UCI Makine Öğrenimi deposundan alınmıştır. Özellik seçimi olmadan ortalama \%89,67, özellik seçim ile ise ortalama olarak \%94,23 doğruluk elde edilmiştir.
\end{abstract}

Anahtar Kelimeler: Parkinson, Derin öğrenme, Genetik algoritma.

\section{Detection of Parkinson's Disease Based on Deep Learning and Feature Selection}

\begin{abstract}
Parkinson's disease is a serious long-term neurodegenerative disease affecting the motor system. It progresses slowly and causes the degeneration of its cells over time. This disease is difficult to diagnose and is one of the common diseases in society. Due to the deficiency of dopamine cells in the brain, it causes motor and non-motor (speech, smell) defects in the body. It is known that most patients with Parkinson's have voice disorders. Speech signals in Parkinson's patients differ greatly compared to normal people. In this study, a method based on deep learning by using the acoustic features of speech signals is proposed for the classification of Parkinson's disease. In the first step, acoustic features are passed through genetic algorithm and effective features are selected. In addition, ReliefF feature selection algorithm is used to compare the performance of genetic algorithm. These features are given as input to the Convolutional Neural Network (CNN) architecture designed in the second step. Experiments are done with a dataset widely used in the literature. This dataset consists of two classes and is taken from the UCI Machine Learning repository. The average accuracy was $89.67 \%$ without feature selection, and $94.23 \%$ on average with feature selection.
\end{abstract}

Keywords: Parkinson, Deep learning, Genetic algorithm.

\footnotetext{
*Sorumlu Yazar: bilal.er@harran.edu.tr
} 


\section{Giriş}

Parkinson hastalığı, dopaminerjik nöronların erken ölümünün neden olduğu ilerleyici bir nörodejeneratif bozukluktur (Poewe et al., 2017). Parkinson hastalığı Alzheimer hastalığından sonra en sık görülen ikinci nörolojik sendromdur (Benba ve ark., 2015). Parkinson hasatlığı, 60 yaşın üzerindeki nüfusun yaklaşık \%1'ini etkilediği tahmin edilmektedir (Reeve ve ark., 2014). Parkinson'un nedeni tam olarak anlaşılamamıştır. Hastalık seyri değişkendir ve farklı oranlarda ilerler. Parkinson hastalığı semptomları çeşitli ilaçlarla tedavi edilebilir (Arena \& Stoessl, 2016). Parkinson hastalığının semptomları motor ve motor dışı olarak sınıflandırılır. Motor semptomlar hareketlerle ilişkilidir ve motor olmayan semptomlara göre daha belirgindir. Motor semptomlarda, hasta hareket yavaşlığından mustariptir. Motor olmayan semptomlar belirli bir aralıkta belirgindir; uyku bozukluğu, konuşma ve yutma problemi ve koku alma bozukluğu gibi semptomlar görünür. Parkinson hastalığının konuşma üzerindeki etkisi fonasyon, artikülasyon ve prozodi olarak karakterize edilir (Parra-Gallego ve ark., 2018). Konuşma sinyalleri genellikle Parkinson hastalığını teşhis etmek için ana yöntemlerden biri olarak kabul edilir (Hosseini-Kivanani ve ark., 2019). Klinisyenler ve konuşma patologları Parkinson hastalarında farklı hastalık durumlarını ayırt etmek için akustik ipuçlarına dayanan öznel yöntemler benimsemiştir (Benba ve ark., 2015). (Hosseini-Kivanani ve ark., 2019) 'da yazarlar, içinde konuşma telaffuz problemlerini tanımlayan üç dilin konuşma sinyali kayıtları üzerinde deneyler yapmıştır. Ünlüler, cümleler, kelimeler gibi konuşma telaffuzunun bu hastalıktan etkilendiği gözlenmektedir. $\mathrm{Bu}$ nedenle konuşma, Parkinson hastalığını tespit etmede önemli bir yöntemdir. Parkinson ile ilgili vokal özelliklerinin otomatik olarak algılanmasına yardımcı olmak için geleneksel yöntemlerin çoğunda, deneklerden hem genlik hem de frekans açısından sabit bir sesli harf üretmeleri istenmektedir (B. E. Sakar ve ark., 2013). Geleneksel Parkinson tespiti çalışmalarında çıkarılan özellikler ile sınıf etiketleri arasındaki ilişkiyi öğrenmek için farklı makine öğrenmesi algoritmaları uygulanmaktadır. Son çalışmaların çoğunda el yazısı ve konuşma veri kümelerini kullanarak hastalık tespiti gerçekleştirmiştir (Rios-Urrego ve ark., 2019; Trinh \& O’Brien, 2019). Parkinson tespiti için çoğunlukla Destek Vektör Makineleri (DVM) ile akustik özellikler dikkate alınmıştır. Ayrıca, literatür de Gauss tabanlı modeller ve ESA'ların Parkinson hastalığı sinıflandırılmasında kullanıldığ görülmektedir.

Bu çalışmada Parkinson sınıflandırmasında derin öğrenmeye dayalı bir yöntem kullanılmaktadır. Öncelikle farklı kategorilerde çıkarılan akustik ses sinyalli özellikleri birleştirilmiştir. Daha sonra etkili özellik seçimi için çıkarılan özellikler genetik algoritmadan geçilmiştir. Son olarak genetik algoritmadan geçirilen özellikler tasarlanan ESA mimarisine girdi olarak verilerek sınıflandırma işlemi yapılmıştır.

$\mathrm{Bu}$ makalenin geri kalanı şu şekilde düzenlenmiştir. Bölüm 2'de literatürdeki çalışmalar gözden geçirilmiştir ve aralarındaki farklar ortaya koyulmuştur. Bölüm 3 ve 4 'te materyal ve önerilen yöntem tanıtılmıştır. Bölüm 5 'te araştırmada kullanılan veri seti ve Parkinson hastalarını tespit edilmesiyle ile ilgili deneysel uygulamalar verilmiştir. Bölüm 6'de ise araştırmanın bulguları tartışılmıştır.

Bu çalışmanın ana katkıları aşağıdaki gibidir:

- Parkinson hastalığının tespiti için özellik seçimi ve derin öğrenmeye dayalı bir yöntem önerilmiştir.
- Derin ağların ağlarının Parkinson hastalığı sınıflandırma problemindeki etkin gücü ortaya koyulmuştur.

- Daha verimli özellikler elde etmek için özellik seçimi algoritması kullanılmıştır.

\section{2. İlgili Çalışmalar}

Parkinson hastalığının sınıflandırılması ile ilgili önemli çalışmalar bu bölümde verilecektir. Örüntü tanıma ve yapay zekanın gelişmesiyle birçok yaklaşım önerilmiştir. (Little ve ark., 2008)'da Parkinson hastalığı olan denekleri sınıflandırmak için yeni bir teknik önermişlerdir. Veriler, 195 sürekli sesli harf fonasyonundan oluşan 31 kişiden toplanmıştır. Bu kişilerin 23'ü Parkinson hastası, 8'i ise sağlıklı bireylerdir. Metodolojileri üç aşamadan oluşmaktadır. Bu aşamalar, özellik çıkarma, ön işleme ve özellik seçimi ve sınıflandırmadır. Sınıflandırma amacıyla, doğrusal çekirdekli DVM kullanılmıştır. Önerilen modelden \%91,4'lük bir doğruluk elde edilmiştir. (Bhattacharya \& Bhatia, 2010)'de sağlıklı denekleri Parkinson hastası deneklerinden ayırmak için Weka olarak bilinen veri madenciliği aracı kullanmıştır. Sınıflandırma amacıyla denetimli bir makine öğrenimi algoritması olan DVM'yi tercih edilmiştir. Sınıflandırmadan önce veri önişlemi veri kümesi üzerinde yapılmıştır. LibSVM kullanılarak mümkün olan en iyi doğruluğu elde etmek için farklı çekirdek değerlendirilmiştir. Doğrusal çekirdekli DVM ile \%65,21 en iyi doğruluğu üretirken, Radyal temelli fonksiyon (RBF) çekirdeği ile \%60,86 doğruluk elde edilmiştir. (B. E. Sakar ve ark., 2013)' de yeni bir model önermişlerdir. Yazarlar verileri 40 denekten (20'si sağlıklı, 20'si Parkinson) toplanmıştır. Her denekten, kısa cümleler, kelimeler, sayılar ve sürekli sesli harfleri içeren 26 ses örneği kaydedilmiştir. Sınıflandırma için DVM ve K en yakın komşu (KNN) kullanılmıştır.1, 3, 5 ve 7 değerleri KNN'deki komşu sayısı için, DVM için ise doğrusal ve RBF çekirdeği tercih edilmiştir. KNN ile \%82,50'lik bir doğruluk, DVM sınıflandırıcısı kullanıldığında ise \%85'lik bir doğruluk sağlanmıştır. (C. O. Sakar ve ark., 2019)' de Parkinson tespiti için farklı konuşma sinyali işleme algoritmaları karşılaştırılmıştır. Çalışmalarında, ayarlanabilir Q faktörü dalgacık dönüşümü (TQWT) olarak adlandırılan yeni bir özellik tanıtılmıştır. Farklı özellik alt kümelerinde, farklı sınıflandırıcılar kullanılarak sınıflandırıcılar eğitilmiştir. Mel Frekans Kepsturm Katsayılarının (MFCC) ve TQWT'nin en yüksek doğruluklara ulaştığı ve bu nedenle Parkinson hastalığını sınıflandırma probleminde önemli özellikler olarak kabul edildiği tespit edilmiştir. Çalışmada ortalama olarak \%86'lık bir doğruluk DVM elde edilmiştir. (Gunduz, 2019)' de vokal özellikler kullanarak Parkinson hastalığını sınıflandırmak için ESA mimarilerine dayanan iki çerçeve önermektedir. Her iki çerçeve de çeşitli özellik kümeleri hem ayrı ayrı hem de birleştirilerek değerlendirilmiştir. İlk yöntemde, 9 katmanlı ESA'ya özellik kümeleri girdi olarak verilmiştir, ikinci yöntemde ise özellik kümelerini doğrudan evrişim katmanlarına bağlı paralel katmanlardan geçirilerek derin özellikler eş zamanlı olarak çıkarılmıştır. Deneysel sonuçlara göre ikinci mimariden daha iyi sonuçlar elde edilmiştir. (Parisi ve ark., 2018)'de Parkinson’un erken teşhisine yardımcı olmak için yeni yapay zekâ temelli yöntem geliştirilmiştir. 68 denekteki disfonik ölçümler ve klinik skorlara ilişkin veriler, UCI Makine Öğrenimi veri tabanından elde edilmiştir. Çok katmanlı bir algılayıcıdan (MLP) türetilmiş ağırlıklar, özellik seçimi için kullanılmıştır. Bu azaltılmış özellik seti daha sonra sınıflandırma için bir Lagrange Destek Vektör Makinesine (LSVM) girdi olarak verilmiştir. Bu hibrit algoritma 
çalışmada kullanılan diğer sınıflandırıcılarla karşılaştırılmıştır. (Ali ve ark., 2019)'de Parkinson tespiti için ses kayıtları kullanılmıştır. Örnek ve özellik seçimi için iki boyutlu bir veri seçme yöntemi önerilmiştir. Önerilen yöntem, ki-kare istatistik modelini kullanarak özellikleri sıralar ve sıralanan özelliklerin optimal alt kümesini arar ve yinelemeli olarak örnekleri seçer. Önerilen yöntem, doğruluk açısından iyi sonuçlar göstermektedir. (Chen ve ark., 2020)'da Hilbert-Huang Transform Dönüşümü (HHT) ve KNN ile ses bozukluklarının sınıflandırılması için yeni bir yöntem önerilmektedir. Her ses kaydının 12 özelliği HHT ile hesaplanmıştır. Ayrıca Linear Prediction Coefficien (LPCC) algoritmasına dayalı olarak, bir örnek 9 özellik ile karakterize edilmiştir. Daha sonra her örnek 21 özellik ile ifade edildikten sonra özellikler KNN sınıflandırıcıya verilmiştir. Ek olarak, KNN sınıflandırıcının performansını değerlendirmek için aynı deneyler rastgele sınıflandırıcı ve karar ağaçları kullanılarak yapılmıştır. Deney sonuçlar, KNN'ye dayalı sınıflandırıcının, \%93,3 doğruluk oranı ile diğer iki sınıflandırıcıdan daha iyi performans gösterdiğini ortaya koymaktadır. (Sivaranjini \& Sujatha, 2019)'de derin sinir ağlar kullanarak sağlıklı ve Parkinson hastası deneklerinin MR görüntüleri sınıflandırılmıştır. Önceden eğitilmiş derin mimari olan AlexNet, Parkinson hastalığının teşhisini iyileştirmek için kullanılmıştır. MR görüntüleri ile önceden eğitilen derin ağ tekrar eğitilmiştir ve sınıflandırma işlemi yapılmıştır. Önerilen sistem ile \%88,9'luk bir doğruluk elde edilmiştir.

\section{Materyal ve Metot}

\subsection{Evrişimsel Sinir Ağları}

Evrişimsel sinir ağları, özellikle görüntü nesnesi tanıma gibi görüntü analizi ve bilgisayarlı görmede başarıyla uygulanmış çok katmanlı, ileri beslemeli yapay sinir ağları gurubundadır. Evrişim ağları beyindeki biyolojik süreçlerden esinlenmiştir. Nöronlar arasındaki bağlantı paterni görsel korteksin organizasyonuna benzer (Fu \& Aldrich, 2019). ESA'lar, görüntü tanıma ve sınıflandırma gibi alanlarda çok etkili olduğu kanıtlanmış bir sinir ağı modelidir (Gülcü \& Kuş, 2019). ESA'lar, minimum ön işleme gerektirecek şekilde tasarlanmıştır. ESA, tipik olarak üç tip katmandan oluşan matematiksel bir yapıdadır. Bu katmanlar evrişim, havuzlama ve tamamen bağlı katmanlardır (Cireundefinedan ve ark., 2011). Evrişimsel ve havuzlama katmanları, özellik çıkarma işlemini gerçekleştirirken, tamamen bağlı katmanlar ise çıkarılan özellikleri, sınıflandırmak için son çıktıya gönderir. Bir sinir ağının görüntüdeki pikselleri sayısal değerler olarak yorumlayabilmesi gerektiğinden evrişimsel katmanlar gereklidir. Evrişimsel katmanların işlevi, görüntüyü sinir ağının yorumlayabileceği sayısal değerlere dönüştürmek ve daha sonra ilgili kalıpları çıkarmaktır. Evrişimsel katmandaki filtreler, görüntüdeki desenleri öğrenecek sonraki katmanlara geçirir. Evrişim katmanında filtreler giriş görüntüsü üzerinde dolaştırılır. Evrişim formülü denklem 1 de verilmiştir. Denklemde verilen ' $M$ ' özellik haritasını, ' $w$ ' ise $(\mathrm{x}, \mathrm{y})$ boyutunda evrişim çekirdeğini ifade eder.

$$
M(i, j)=\left(R^{*} w\right)(i, j)=\sum_{x} \quad \sum_{y} R(i-x, j-y) w(x, y)
$$

Her evrişim katmanından sonra, doğrusal olmayan bir katmanın veya aktivasyon katmanının uygulanması ESA'ada gelenekseldir. $\mathrm{Bu}$ katmanın amacı, temelde doğrusal işlemleri hesaplayan bir sistemi doğrusal olmayan hale getirmektir. ReLU katmanı, gelen tüm değerlere $\mathrm{f}(\mathrm{x})=\max (0, \mathrm{x})$ işlevini uygular.
Temel olarak, bu katman tüm negatif aktivasyonları 0 olarak değiştirir. $\mathrm{Bu}$ katman, evrişim katmanından gelen özellikleri etkilemeden modelin ve genel ağın doğrusal olmayan özelliklerini arttırır. ReLu için gerekli formül denklem 2'de verilmiştir.

$$
\operatorname{ReLU}(x)=\max (x, 0)
$$

Havuzlama (pooling) katmanı bir ESA'nın başka bir yap1 taşıdır ve evrişim ve ReLu işleminden sonra uygulanır. İşlevi, ağdaki parametre ve hesaplama miktarını azaltmaktır. Havuzlama katmanı her özellik haritasından bağımsız olarak çalışır. Havuzlamada kullanılan en yaygın yaklaşım maksimum havuzlamadır. Şekil 1'de maksimum havuzlama (maxpooling) örneği gösterilmektedir.

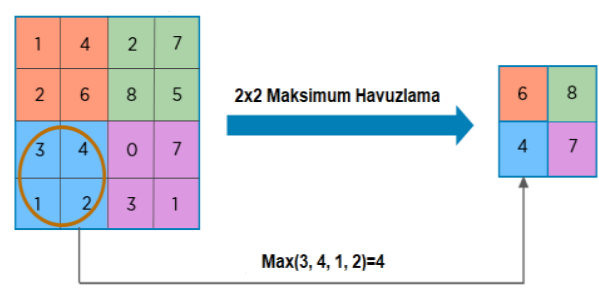

Şekil 1. Maksimum Havuzlama Örneği

Evrişim ve havuzlama katmanları tarafindan alt örneklenen özellikler oluşturulduktan sonra bu özellikler tam bağlı katmana bağlanır. Son evrişim veya havuzlama katmanının çıktı özellik haritaları tipik olarak düzleştirilir, yani bir boyutlu (1D) sayı dizisine veya vektöre dönüştürülür. Daha sonra bu özellikler bir veya daha fazla tamamen bağlı katmana bağlanır. Burada her girdi her bir çıktıya bağlanır ve her bir nöron öğrenilebilir ağırlığa sahiptir. Son tam bağlı katman tipik olarak sınıf sayısıyla aynı sayıda çıkış düğümüne sahiptir ve bu katmanda sınıflandırma işlemi yapılır. Son katmanda farklı sınıflandırıcılar kullanılabileside genellikle Softmax kullanılır. Softmax denklemi 3 'te verilmiştir. Softmax, nöronların çıkış değerlerini $(0,1)$ aralığında olmasını sağlar.

$$
\operatorname{softmax}(x)_{j}=\frac{e^{x_{i}}}{\sum_{\mathrm{n}=1}^{\mathrm{N}} \mathrm{e}^{\mathrm{x}_{n}}}, \quad j=1 \ldots \ldots . N
$$

\subsection{Genetik Algoritma ile Özellik Seçimi}

Evrimsel hesaplama, optimizasyon için bir araç olarak kullanılabileceği düşüncesiyle geliştirilmiştir. Genetik Algoritma (GA), genetik ve doğal seleksiyon prensiplerine dayanan arama tabanlı bir optimizasyon tekniğidir. GA, kromozom popülasyonunu, çaprazlama ve mutasyon gibi işlemlere birlikte yeni popülasyonlara dönüştürmenin bir yöntemidir ( $\mathrm{Wu}$ ve ark., 2013). Genellikle çözülmesi uzun sürecek problemlere optimal çözümler bulmak için kullanılır (Koza, 1994). Makine öğreniminde optimizasyon problemlerini çözmek için sıklıkla kullanılır. $\mathrm{Bu}$ çalışmada özellik seçimi için en gelişmiş algoritmalardan biri olan GA kullanılmıştır. GA tabanlı özellik seçiminde yer alan adımlar şunlardır;

$\checkmark$ Başla: İlk adım, popülasyondaki bireyleri oluşturmak ve başlatmaktır. GA optimizasyon yöntemi olduğundan, bireylerin genleri genellikle rastgele başlatılır.

$\checkmark$ Uygunluk: Başlatma işleminden sonra, popülasyondaki her bireye bir uygunluk değeri atamak gerekir. Uygunluk değeri karşılanırsa, sonucu sonlandırmak ve sonucu üretmek anlamına gelir, aksi takdirde sonraki adımlar izlenir. 
$\checkmark$ Seçim: Seçim operatörü bir sonraki nesil için yeniden birleştiren özellikleri seçer. Mevcut popülasyondaki en iyi bireyler seçilir. Uygunluk değerine en yakın olanların seçim şansı daha yüksektir.

$\checkmark$ Çaprazlama: Seçim operatörü popülasyonun yarısını seçtikten sonra, çaprazlama operatörü yeni bir popülasyon oluşturmak için seçilen kişileri yeniden birleştirir.

$\checkmark$ Mutasyon: Çaprazlama operatörü, ebeveynlere çok benzeyen bireyler üretebilir. $\mathrm{Bu}$, düşük çeşitliliğe sahip yeni bir nesle neden olabilir. Mutasyon operatörü bu sorunu, bireylerin bazı özelliklerin değerini rastgele değiştirerek çözer.

\subsection{ReliefF ile Özellik Seçimi}

ReliefF, birçok özellik seçim uygulamasında başarılı sonuçlar veren en önemli özellik seçimi algoritmalardan biridir. ReliefF, Relief istatistiksel modelinin geliştirilmiş versiyonudur.
Relief metodu, veri setinden bir örnek ele alarak ilgili örneğin, kendi sınıflarındaki diğer örneklerle yakınlığını ve farklı sınıflarla olan uzaklığına bağlı bir model oluşturarak özellik seçme işlemini gerçekleştirmektedir (Bolón-Canedo ve ark., 2014).

\section{4. Önerilen Yöntem}

Parkinson hastalığının sınıflandırılması için önerilen yöntem üç adımdan oluşmaktadır. İlk olarak ses sinyallerinden farklı kategorilerde elde edilen özellikler birleştirilmiştir. Birleştirilmiş özelliklerden en belirgin özellikleri seçmek için genetik algoritma kullanılmıştır. Daha sonra ise en belirgin özellikler tasarlanan ESA modeline girdi olarak verilerek sinıflandırma işlemi yapılmıştır. Ayrıca tasarlanan ağın performansını ölçmek için farklı kategorideki özellikler ayrı ayrı derin ağa girdi olarak verilmiştir. Önerilen yöntem şekil 2'de sunulmuştur. Ayrıca Genetik algoritmanın performansını ölçmek için aynı deneyler ReliefF özellik seçimi ile de yapılmıştır.

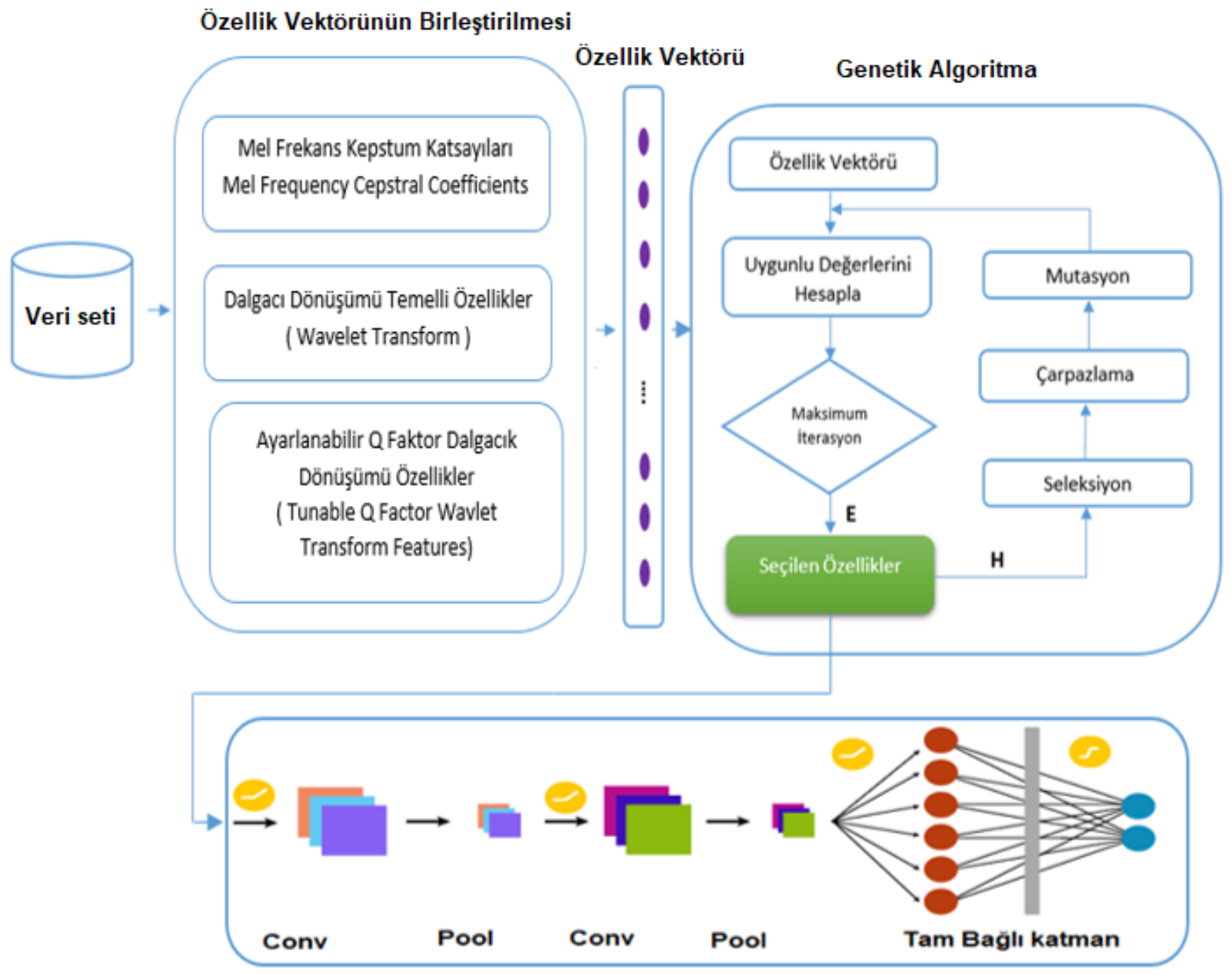

Şekil 2. Önerilen Yöntem

\subsection{ESA'nın Tasarımı}

Tasarlanan ESA'nın topolojisi, 1 giriş katmanı,2 evrişim katmanı, 2 havuzlama katmanı, iki tam bağlantılı katmanı ve 1 çıkış katmanından oluşur. Tasarlanan mimaride toplam 8 katman bulunmaktadır. Birinci evrişim katmanında 128 adet evrişim filtresi, ikinci evrişim katmanında 64 adet evrişim filtresi bulunmaktadir. Aktivasyon fonksiyonu olarak ReLu kullanılmıştır. Ayrıca her evrişim ve ReLu işleminden sonra 2x1 boyutunda maksimum havuzlama yapılmıştır. Tasarlanan mimari Tablo 1'de verilmiştir.

Tablo 1. Tasarlanan ESA mimarisi

\begin{tabular}{l|l|l|l}
\hline No & Katman İsmi & Açılama & Özellikler \\
\hline
\end{tabular}


Avrupa Bilim ve Teknoloji Dergisi

\begin{tabular}{l|l|l|l}
\hline 1 & Giriş & Giriş vektörü & - \\
\hline 2 & 'conv1' & Evrişim & 12 boyutunda 128 adet evirşim filtresi \\
\hline 3 & 'relu1' & ReLu & - \\
\hline 4 & 'pool1' & Maksimum Havuzlama & 2 x1 havuzlama \\
\hline 5 & 'conv2' & Evrişim & 6 boyutunda 64 adet evrşim filtresi \\
\hline 6 & 'relu2' & ReLu & - \\
\hline 7 & 'pool2' & Maksimum Havuzlama & $2 \times 1$ havuzlama \\
\hline 8 & 'fc1' & Tam Bağl1 Katman & 2048 nöron \\
\hline 9 & 'relu7' & ReLu & - \\
\hline 10 & 'drop7' & Dropout & $50 \%$ dropout \\
\hline 11 & 'fc2' & Tam Bağlı Katman & 1024 nöron \\
\hline 12 & Çık1s & Softmax & 2 sinıf \\
\hline
\end{tabular}

\section{Deneysel Uygulamalar}

\subsection{Veri Seti}

$\mathrm{Bu}$ çalışmada UCI Makine Öğrenimi deposundan alınan veri seti kullanılmıştır. Veriler, İstanbul Üniversitesi Cerrahpaşa Tıp Fakültesi Nöroloji Anabilim Dalı'nda bulunan 33 ile 87 yaşları arasında 107 erkek ve 81 kadından oluşan hastalardan toplanmıştır (C. O. Sakar ve ark., 2019). Sağlıklı bireyler, 41 ile 82 yaş arası 23 erkek ve 41 kadından oluşmaktadır. Veri setinde 188 Parkinson hastasından ve 64 sağlıklı bireyden alınan 756 kayıt vardır. Her bireyden üç ses kaydı alınmıştır. Veri setinden klinik olarak değerli bilgileri elde etmek amacıyla Zaman frekans1 özellikleri, Mel frekans kepstral katsayıları, dalgac1 dönüşümü temelli özelikler, ayarlanabilir $\mathrm{Q}$ faktör dalgacık dönüşümü özellikler ve vokal özellikler vardır. Çeşitlendirilmiş konuşma sinyali işleme algoritmaları ile 754 özellikler çıarılmıştır ve bu özellikler veri setinde hazır olarak verilmiştir. Zaman frekans özellikleri, sinyallerin frekans uzayına taşınması ile elde edilen DB cinsinden ortalama, minimum ve sinyalin gücü şeklindeki özelliklerdir (C. O. Sakar ve ark., 2019). MFCC, insan işitme algılamasına dayanmaktadır ve ses işeme alanında en çok kullanılan özellik çıkarma yöntemlerinden biridir. MFCC özellikleri insan kulağının frekans seçiciliğini taklit ederek konuşmacıları ayırt edici değerler elde edilmesi üzerine kurulmuştur. MFCC, Parkinson'dan etkilenen dil ve dudaklardaki hareket değişikliklerinin tespiti için yararlı olmuştur (B. E. Sakar ve ark., 2013). Konuşma örneklerinin ham temel frekans (F0) konturundan elde edilen dalgacık dönüşümü tabanlı özellikler, Birleşik Parkinson Hastalığı Derecelendirme Ölçeğinin (UPDRS) göstergeleri olarak kullanılmıştır. Dalgacık dönüşümü tabanlı özelliklerin kullanımının arkasındaki fikir, sürekli bir sesli harfin periyodik olarak tekrarlanması, sağlıklı konuşma örnekleri için minimum olmasıdır (Titze, 2000). Ayarlanabilir Q faktörü dalgacık dönüşümü özellikler, iki bantlı bir sinyalin alt kısmının düşük geçişli bir ölçeklendirme filtresi ve yüksek geçişli bir ölçekleme filtresi ile yinelemeli olarak filtrelenmesi ile elde edilir (Selesnick, 2011). Temel özellikler olarak bilinen ve en yaygın kullanılan vokal özellikleri titreme, parıltt, temel frekans parametreleri, harmonite parametreleridir (C. O. Sakar ve ark., 2019).

\subsection{Deneysel Sonuçlar}

$\mathrm{Bu}$ çalışmada sınıflandırma işlemi için ses kayıtlarından elde edilen özellikler ve tasarlanan ESA mimarisi kullanılmıştır. e-ISSN: 2148-2683
Önerilen yöntemin başarım kriterleri doğruluk, kesinlik ve Fskoru oranlarına dayalı olarak yapılmıştır.

- Yanlış pozitifler (YP): negatif sınıftan olan, pozitif olarak tahmin edilen örnekler.

- Yanlış negatifler (YN): gerçek sınıfı pozitif olan negatif olarak tahmin edilen örnekler.

- Doğru pozitifler (DP): pozitif sınıfa ait doğru tahmin edilen örnekler.

- Doğru negatifler (DN): negatif sınıfa ait olarak doğru tahmin edilen örnekler.

$$
\text { Doğruluk }=\frac{|D N|+|D P|}{|Y N|+|Y P|+|D N|+|D P|}
$$

Kesinlik (P), pozitif bir tahminin doğru olma olasılığını tahmin eden bir ölçüdür. Kesinlik ölçümü denklem 5 'te verilmiştir.

$$
\operatorname{Kesinlik}(P)=\frac{|D P|}{|D P|+|Y P|}
$$

F-skoru, pozitif kestirim oranı ve duyarlılık ölçülerinin uyumlu bir ortalaması olup denklem 6'de gösterildiği gibi hesaplanır.

$$
F-s k o r=\frac{2 *|D P|}{2 *|D P|+|Y P|+|Y N|}
$$

Öğrenme oranı, epok sayısı ve minibatch boyutu ESA'nın performansını etkileyen en önemli hiper parametrelerdir. Tasarlanan mimaride minibatch boyutu 16, maksimum epok sayıs1 20 ve öğrenme oranı 1e-6 olarak ayarlanmıştır. Bu parametrelerin seçilme nedeni tasarlanan mimari için en optimum sonucu vermelerdir. Eğitim ve test için ayrılan verilerin boyutunun performans üzerindeki etkisini görmek için, bu veriler 2 farklı şekilde bölünmüştür. İlk deneyde, verilerin \%70'i eğitim için ve \%30'ı test için kullanılır; ikinci deneyde, verilerin $\% 80$ 'i eğitim için ve \%20'si test için kullanılmıştır. Verilerin eğitim ve test için sırasıyla \%70-\%30 olarak bölünmesi ile elde edilen sınıflandırma sonuçları Tablo 2'de verilmiştir. Deneyler, Zaman frekans özellikleri, MFCC, Dalgacı dönüşümü temelli özelikler, ayarlanabilir Q faktör dalgacık dönüşümü özellikler ve vokal özellikler kullanılarak yapılmıştır. Ayrıca, bu özellikler birleştirilerek aynı deneyler tekrar yapılmıştır. Son olarak birleştirilmiş özellik vektörü hem ReliefF hem de genetik algoritmadan geçirilerek özellik seçimi yapılmışıtır. Veri setindeki 754 özellik ReliefF özellik seçimi ile 372'ye genetik algoritma ile ise 361 'ye indirilmiştir. Zaman frekans özellikleri kullanılarak \%82,13, MFCC özellik vektörü kullanılarak $\% 83,25$, dalgacı dönüşümü temelli özelik vektörü kullanılarak 
\%85,46, ayarlanabilir Q faktör dalgacık dönüşümü özellikler kullanılarak \%85,90 ve vokal özellik vektörü ile ise $\% 81,35$ genel doğruluk elde edilmiştir. Özellik seçimi olmadan birleştirilmiş özellik vektörü kullanılarak \%88,34, ReliefF özellik seçimi işlemi yapılarak birleştirilmiş özellik vektöründen \%91,67 ve genetik algoritmadan geçirilmiş birleştirilmiş özellik vektöründen ise \%93,56 genel doğruluk elde edilmiştir. En iyi sınıflandırma sonucuna genetik algoritmadan geçirilmiş birleştirilmiş özellik vektöründen elde edilmiştir. En iyi sınıflandırma sonucuna ait karışıklık matrisi şekil 3’te verilmiştir. Genetik algoritmadan geçirmiş özellik vektörü için eğitim ve test sıralarındaki doğruluk ve kayıp sonuçları şekil 4 'de verilmiştir.

Tablo 2. Verinin Eğitim ve Test için \%70-\%30 Olarak Bölünmesi ile Elde Edilen Sınıflandırma Sonuçları

\begin{tabular}{|c|c|c|c|}
\hline Özellik Vektörü & $\begin{array}{c}\text { Doğruluk } \\
\%\end{array}$ & $\begin{array}{c}\text { Kesinlik } \\
\%\end{array}$ & $\begin{array}{c}\text { F-skoru } \\
\%\end{array}$ \\
\hline Zaman Frekansı Özellikleri & 82,13 & 83,46 & 83,57 \\
\hline MFCC & 83,25 & 88,30 & 88,23 \\
\hline Dalgacı dönüşümü temelli özelikler & 85,46 & 88,20 & 90,48 \\
\hline Ayarlanabilir Q faktör dalgacık dönüşümü özellikler & 85,90 & 90,53 & 90,53 \\
\hline Vokal özellikler & 81,35 & 82,37 & 81,42 \\
\hline Birleştirilmiş özellik vektörü (Özellik seçimi olmadan) & 88,34 & 91,34 & 91,27 \\
\hline Birleştirilmiş özellik vektörü (ReliefF ile özellik seçimli) & 91,67 & 91,35 & 91,82 \\
\hline Birleştirilmiş özellik vektörü (Genetik algoritma ile özellik seçimli) & 93,56 & 93,24 & 93,02 \\
\hline
\end{tabular}

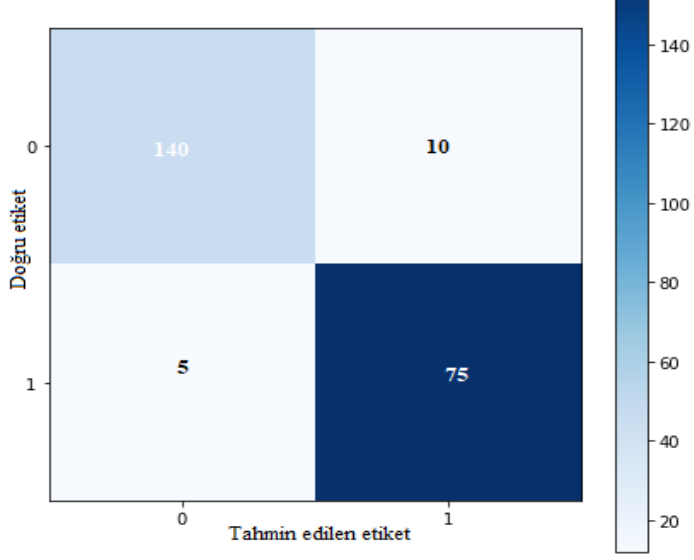

Şekil 3. En İyi Sınıflandırma Sonucuna Ait Karışıklık Matrisi (Verinin Ĕ̆itim ve Test için Bölünme Oranı: \%70-\%30)
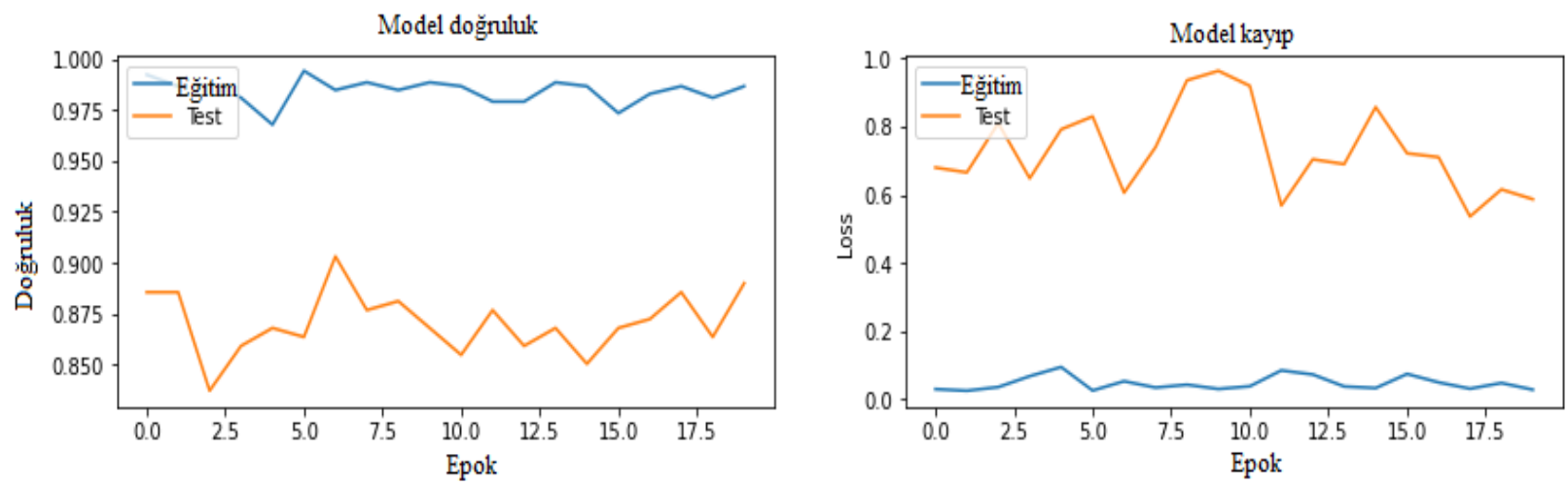

Şekil 4. Öğrenme Grafikleri (Verinin Ĕgitim ve Test için Bölünme Oranı: \%70-\%30)

Verilerin eğitim ve test için sırasıyla \%80-\%20 olarak bölünmesi ile elde edilen sınıflandırma sonuçları Tablo 3 'te verilmiştir. Zaman frekans özellikleri kullanılarak \%82,79, MFCC özellik vektörü kullanılarak \%84,25, dalgacı dönüşümü temelli özelik vektörü kullanılarak \%86,21, ayarlanabilir Q faktör dalgacık dönüşümü özellikler kullanılarak \%86,53 ve vokal özellik vektörü ile ise \%83,56 genel doğruluk elde edilmiştir. Özellik 
seçimi olmadan birleştirilmiş özellik vektörü kullanılarak \%89,67, ReliefF özellik seçimi işlemi yapılarak birleştirilmiş özellik vektöründen $\% 93,15$ ve genetik algoritmadan geçirilmiş birleştirilmiş özellik vektöründen ise \%94,23 genel doğruluk elde edilmiştir. En iyi sınıflandırma sonucuna genetik algoritmadan geçirilmiş birleştirilmiş özellik vektöründen elde edilmiştir. En iyi sınıflandırma sonucuna ait karışıklık matrisi şekil 5'te verilmiştir. Genetik algoritmadan geçirmiş özellik vektörü için eğitim ve test sıralarındaki doğruluk ve kayıp sonuçları şekil 6 'da verilmiştir. Verilerin test ve eğitim için farklı oranlarda bölünmesi ile elde edilen deney sonuçları arasındaki standart sapmalar Tablo 4'te verilmiştir. Performans değerlendirmesi için elde ettiğimiz bulgularla literatürde kullanılan diğer yöntemlerden elde edilen sonuçlar karşılaştırılmıştır. Tablo 5'te önemli bazı çalışmalar verilmiştir.

Tablo 3. Verinin Eğitim ve Test için \%80-\%20 Olarak Bölünmesi ile Elde Edilen Stnıflandırma Sonuçları

\begin{tabular}{|c|c|c|c|}
\hline Özellik Vektörü & $\begin{array}{c}\text { Doğruluk } \\
\%\end{array}$ & $\begin{array}{c}\text { Kesinlik } \\
\%\end{array}$ & $\begin{array}{c}\text { F-skoru } \\
\%\end{array}$ \\
\hline Zaman Frekansı Özellikleri & 82,79 & 84,15 & 84,15 \\
\hline MFCC & 84,25 & 86,67 & 88,69 \\
\hline Dalgacı dönüşümü temelli özelikler & 86,21 & 89,50 & 91,57 \\
\hline Ayarlanabilir Q faktör dalgacık dönüşümü özellikler & 86,53 & 91,67 & 92,45 \\
\hline Vokal özellikler & 83,56 & 83,56 & 82,87 \\
\hline Birleştirilmiş özellik vektörü (Özellik seçimi olmadan) & 89,67 & 91,35 & 91,89 \\
\hline Birleştirilmiş özellik vektörü (ReliefF ile özellik seçimli) & 93,15 & 92,67 & 93,12 \\
\hline Birleştirilmiş özellik vektörü (Genetik algoritma ile özellik seçimli) & 94,23 & 93,56 & 94,34 \\
\hline
\end{tabular}

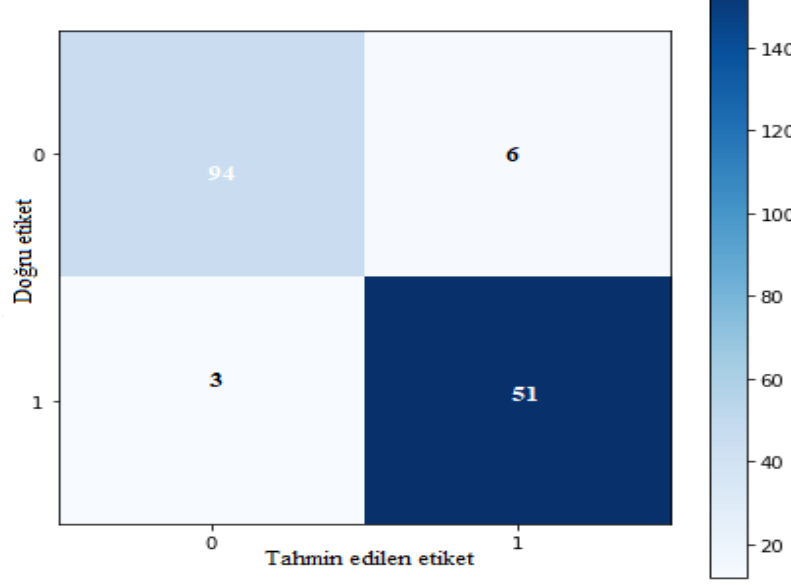

Şekil 5. En Iyi Sınıflandırma Sonucuna Ait Karışıklık Matrisi (Verinin Eğitim ve Test için Bölünme Oranı: \%80-\%20)
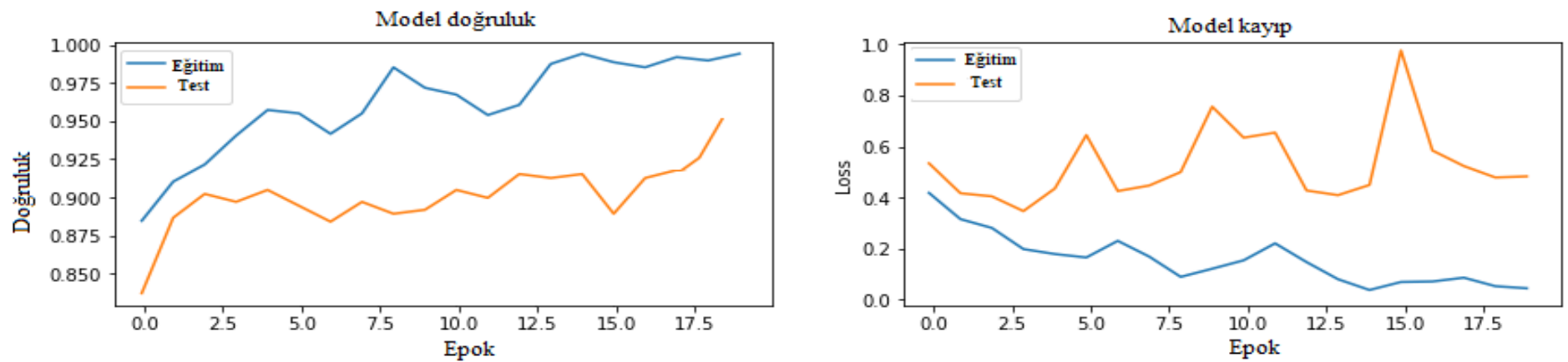

Şekil 6. Öğrenme Grafikleri (Verinin Ĕgitim ve Test için Bölünme Oranı: \%80-\%20)

Tablo 4. Deney Sonuçları Arasındaki Standart Sapmalar

\begin{tabular}{|c|c|c|c|} 
Özellik Vektörü & Doğruluk & Kesinlik & F-skoru \\
& için Standart Sapma & için Standart Sapma & için Standart Sapma \\
\hline
\end{tabular}


European Journal of Science and Technology

\begin{tabular}{c|c|c|c}
\hline Zaman Frekansı Özellikleri & 0,33 & 0,345 & 0,29 \\
\hline MFCC & 0,5 & 0,815 & 0,23 \\
\hline Dalgacı dönüşümü temelli özelikler & 0,375 & 0,65 & 0,545 \\
\hline $\begin{array}{c}\text { Ayarlanabilir Q faktör dalgacık } \\
\text { dönüşümü özellikler }\end{array}$ & 0,315 & 0,57 & 0,96 \\
\hline Vokal özellikler & 1,105 & 0,595 & 0,725 \\
\hline $\begin{array}{c}\text { Birleştirilmiş özellik vektörü (Özellik } \\
\text { seçimi olmadan) }\end{array}$ & 0,665 & 0,005 & 0,31 \\
\hline $\begin{array}{c}\text { Birleştirilmiş özellik vektörü (ReliefF } \\
\text { ile özellik seçimli) }\end{array}$ & 0,74 & 0,66 & 0,65 \\
\hline $\begin{array}{c}\text { Birleştirilmiş özellik vektörü (Genetik } \\
\text { algoritma ile özellik seçimli) }\end{array}$ & 0,335 & 0,16 & 0,66 \\
\hline
\end{tabular}

Tablo 5. Performans Karşılaştııılması

\begin{tabular}{c|c|c}
\hline Yötem & Sinıflandırıcı & Doğruluk \% \\
\hline Sakar ve ark. (C. O. Sakar ve ark., 2019) & DVM (RBF) & 86,0 \\
\hline Sakar ve ark. (C. O. Sakar ve ark., 2019) & KNN & 85,0 \\
\hline Xiong ve ark. (Xiong \& Lu, 2020) & LDA (Lineer Diskriminant Analizi) & 95.0 \\
\hline Gündüz (Gunduz, 2019) & ESA (Parelel evrişim) & 86,69 \\
\hline Önerilen Yöntem & ESA & 94,23 \\
\hline
\end{tabular}

\section{Sonuç}

Parkinson hastalığı dünya çapında insanlar arasında yaygın görülen hastalıklardan biridir. Hastalığın erken teşhisi açık bir araştırma konusudur ve birçok araştırmacı, tespiti ve teşhis için en yüksek doğruluğa ulaşmada önemli çalışmalar yapmıştır. Hesaplamalı modeller tıbbi hastalık tanısında etkilidir ve veriler birincil faktördür. $\mathrm{Bu}$ deneysel çalışmada, ses kayıtlarından Parkinson hastalığının tespiti için derin ağlara dayalı bir yöntem önerilmiştir. Önerilen yöntemde kullanılan veri seti UCI Makine Öğrenimi deposundan alınmıştır. İlk olarak farklı kategorideki özellik vektörleri birletilmiştir. Etkin özellikleri seçmek için

\section{Kaynakça}

Ali, L., Zhu, C., Zhou, M., \& Liu, Y. (2019). Early diagnosis of Parkinson's disease from multiple voice recordings by simultaneous sample and feature selection. Expert Systems with Applications, 137, 22-28. https://doi.org/10.1016/j.eswa.2019.06.052

Arena, J. E., \& Stoessl, A. J. (2016). Optimizing diagnosis in Parkinson's disease: Radionuclide imaging. Parkinsonism \& Related Disorders, 22, S47-S51. https://doi.org/10.1016/j.parkreldis.2015.09.029

Benba, A., Jilbab, A., \& Hammouch, A. (2015). Detecting Patients with Parkinson's disease using Mel Frequency Cepstral Coefficients and Support Vector Machines. International Journal on Electrical Engineering and Informatics, Volume 7, 297-307. https://doi.org/10.15676/ijeei.2015.7.2.10

Bhattacharya, I., \& Bhatia, M. P. S. (2010). SVM classification to distinguish Parkinson disease patients. In Proceedings of the 1st Amrita ACM-W Celebration on Women in Computing in India - $A 2 C W i C$ '10. ACM Press. https://doi.org/10.1145/1858378.1858392 birleştirilmiş özellik vektörü özellik seçme algoritmalarından geçirilmiştir. Daha sonra tasarlanan ESA mimarisine özellikler girdi olarak verilerek sınıflandırma işlemi yapılmıştır. Özellik seçimi olmadan \%89,67, genetik algoritma ile özellik seçim sonrası ise \%94,23 doğruluk elde edilmiştir. Sonuçlar, kullanılan yöntemin sağlıklı ve Parkinson hastasını ayırt etmede etkili olduğunu göstermektedir. Gelecekteki çalışmalar için ESA ve Uzun Kisa Vadeli Hafiza (LSTM) hibrit modellerinin Parkinson hasatlığının sinıflandırma probleminde kullanılası önerilmektedir.

Bolón-Canedo, V., Sánchez-Maroño, N., Alonso-Betanzos, A., Benítez, J. M., \& Herrera, F. (2014). A review of microarray datasets and applied feature selection methods. Information Sciences, 282, 111-135. https://doi.org/10.1016/j.ins.2014.05.042

Chen, L., Wang, C., Chen, J., Xiang, Z., \& Hu, X. (2020). Voice Disorder Identification by using Hilbert-Huang Transform (HHT) and K Nearest Neighbor (KNN). Journal of Voice. https://doi.org/10.1016/j.jvoice.2020.03.009

Cireundefinedan, D. C., Meier, U., Masci, J., Gambardella, L. M., \& Schmidhuber, J. (2011). Flexible, High Performance Convolutional Neural Networks for Image Classification. Proceedings of the Twenty-Second International Joint Conference on Artificial Intelligence - Volume Volume Two, 1237-1242.

Fu, Y., \& Aldrich, C. (2019). Flotation froth image recognition with convolutional neural networks. Minerals Engineering, 132, 183-190. https://doi.org/10.1016/j.mineng.2018.12.011

GÜLCÜ, A., \& KUŞ, Z. (2019). Konvolüsyonel Sinir Ağlarında Hiper-Parametre Optimizasyonu Yöntemlerinin İncelenmesi. In Gazi Üniversitesi Fen Bilimleri Dergisi 
Part C: Tasarım ve Teknoloji (Vol. 7, pp. 503-522). Gazi Üniversitesi. https://doi.org/10.29109/gujsc.514483

Gunduz, H. (2019). Deep Learning-Based Parkinson's Disease Classification Using Vocal Feature Sets. IEEE Access, 7, 115540-115551.

https://doi.org/10.1109/access.2019.2936564

Hosseini-Kivanani, N., Vásquez-Correa, J. C., Stede, M., \& Nöth, E. (2019). Automated Cross-language Intelligibility Analysis of Parkinson's Disease Patients Using Speech Recognition Technologies. In Proceedings of the 57th Annual Meeting of the Association for Computational Linguistics: Student Research Workshop. Association for Computational https://doi.org/10.18653/v1/p19-2010

Linguistics.

Koza, J. R. (1994). Genetic programming as a means for programming computers by natural selection. Statistics and Computing, 4(2), 87-112. https://doi.org/10.1007/BF00175355

Little, M., McSharry, P., Hunter, E., Spielman, J., \& Ramig, L. (2008). Suitability of dysphonia measurements for telemonitoring of Parkinson's disease. Nature Precedings. https://doi.org/10.1038/npre.2008.2298.1

Parisi, L., RaviChandran, N., \& Manaog, M. L. (2018). Featuredriven machine learning to improve early diagnosis of Parkinson's disease. Expert Systems with Applications, 110, 182-190. https://doi.org/10.1016/j.eswa.2018.06.003

Parra-Gallego, L. F., Arias-Vergara, T., Vásquez-Correa, J. C., Garcia-Ospina, N., Orozco-Arroyave, J. R., \& Nöth, E. (2018). Automatic Intelligibility Assessment of Parkinson's Disease with Diadochokinetic Exercises. In Communications in Computer and Information Science (pp. 223-230). Springer International Publishing. https://doi.org/10.1007/978-3-030-00353-1_20

Poewe, W., Seppi, K., Tanner, C. M., Halliday, G. M., Brundin, P., Volkmann, J., Schrag, A.-E., \& Lang, A. E. (2017). Parkinson disease. Nature Reviews Disease Primers, 3(1). https://doi.org/10.1038/nrdp.2017.13

Reeve, A., Simcox, E., \& Turnbull, D. (2014). Ageing and Parkinson's disease: why is advancing age the biggest risk factor? Ageing Research Reviews, 14(100), 19-30. https://doi.org/10.1016/j.arr.2014.01.004

Rios-Urrego, C. D., Vásquez-Correa, J. C., Vargas-Bonilla, J. F., Nöth, E., Lopera, F., \& Orozco-Arroyave, J. R. (2019). Analysis and evaluation of handwriting in patients with Parkinson's disease using kinematic, geometrical, and nonlinear features. Computer Methods and Programs in Biomedicine, 173, 43-52. https://doi.org/10.1016/j.cmpb.2019.03.005

Sakar, B. E., Isenkul, M. E., Sakar, C. O., Sertbas, A., Gurgen, F., Delil, S., Apaydin, H., \& Kursun, O. (2013). Collection and Analysis of a Parkinson Speech Dataset With Multiple Types of Sound Recordings. IEEE Journal of Biomedical and Health Informatics, 17(4), 828-834. https://doi.org/10.1109/jbhi.2013.2245674

Sakar, C. O., Serbes, G., Gunduz, A., Tunc, H. C., Nizam, H., Sakar, B. E., Tutuncu, M., Aydin, T., Isenkul, M. E., \& Apaydin, H. (2019). A comparative analysis of speech signal processing algorithms for Parkinson's disease classification and the use of the tunable Q-factor wavelet transform. Applied Soft Computing, 74, 255-263. https://doi.org/10.1016/j.asoc.2018.10.022

Selesnick, I. W. (2011). Wavelet Transform With Tunable QFactor. IEEE Transactions on Signal Processing, 59(8),
3560-3575. https://doi.org/10.1109/TSP.2011.2143711

Sivaranjini, S., \& Sujatha, C. M. (2019). Deep learning based diagnosis of Parkinson's disease using convolutional neural network. Multimedia Tools and Applications, 79(21-22), 15467-15479. https://doi.org/10.1007/s11042$019-7469-8$

Titze, I. R. (2000). Principles of Voice Production, National Center for Voice and Speech. Acoustical Society of America.

Trinh, N. H., \& O’Brien, D. (2019). Pathological Speech Classification Using a Convolutional Neural Network. In Proc. IMVIP, Ireland.

Wu, T.-C., Hung, K.-C., Liu, J.-H., \& Liu, T.-K. (2013). Wavelet-based ECG data compression optimization with genetic algorithm. Journal of Biomedical Science and Engineering, 06(07), 746-753. https://doi.org/10.4236/jbise.2013.67092

Xiong, Y., \& Lu, Y. (2020). Deep Feature Extraction From the Vocal Vectors Using Sparse Autoencoders for Parkinson's Classification. IEEE Access, 8, 27821-27830. https://doi.org/10.1109/access.2020.2968177 